\title{
BAFF is involved in macrophage-induced bortezomib resistance in myeloma
}

\author{
Jing Chen ${ }^{1,3}$, Donghua He ${ }^{1,3}$, Qingxiao Chen ${ }^{1}$, Xing Guo ${ }^{1}$, Li Yang ${ }^{1}$, Xuanru Lin ${ }^{1}$, Yi Li ${ }^{1}$, Wenjun Wu${ }^{1}$, Yang Yang ${ }^{1}$, Jingsong He${ }^{1}$, \\ Enfan Zhang ${ }^{1}$, Qing $\mathrm{Yi}^{2}$ and Zhen Cai ${ }^{* 1}$
}

We aimed to characterize the role of B-cell activating factor (BAFF) in macrophage-mediated resistance of multiple myeloma (MM) cells to bortezomib (bort), and to further understand the molecular mechanisms involved in the process. First, we detected BAFF and its three receptors on myeloma cells and macrophages using the quantitative reverse transcriptase-polymerase chain reaction and flow cytometry. The secretion of BAFF was tested in patients with MM, MM cell lines, and macrophages. The ability of macrophages to protect MM cells from bort-induced apoptosis was significantly attenuated using BAFF-neutralizing antibody in the co-culture system or knocking down the expression of BAFF in macrophages with small interfering RNA. We also showed that the MM-macrophage interaction through BAFF and its receptors was primarily mediated by the activation of Src, Erk1/2, Akt, and nuclear factor kappa B signaling and the suppression of caspase activation induced by bort. Our data demonstrated that BAFF played a functional role in the macrophage-mediated resistance of MM cells to bort, suggesting that targeting BAFF may provide a basis for the molecular- and immune-targeted therapeutic approach.

Cell Death and Disease (2017) 8, e3161; doi:10.1038/cddis.2017.533; published online 2 November 2017

Multiple myeloma (MM) is a universally clonal B-cell neoplasm characterized by the expansion of malignant plasma cells in the hematopoietic bone marrow (BM). ${ }^{1} \mathrm{MM}$ cells are protected from both spontaneous and drug-induced apoptosis as a consequence of adhesion to certain microenvironmental components. ${ }^{2}$ Bortezomib (bort, Velcade) is one of the best effective treatments for MM. It has simultaneously targeted MM cells and their closely supportive BM environment. ${ }^{3}$ Although initial advantages of bort treatment of MM including higher overall response rates are promising, a number of patients develop a resistance to it over time..$^{4,5}$

To date, the mechanism of bort resistance is unknown. Recent studies have shown that MM cells do manifest a clonal heterogeneity, ${ }^{6}$ and their mutation or overexpression of bortbinding protein at the $\beta 5$ proteasome subunit ${ }^{7}$ may result in the acquired resistance to bort. The upregulation of insulin-like growth factor-1, heat shock proteins, $\beta$-catenin/Wnt, and c-Met/phosphor c-Met has been suggested. ${ }^{8}$ Bort resistance has also been related to the activation of prosurvival autophage $^{8}$ and alterations in bone marrow stromal cells (BMSCs). ${ }^{9}$

Tumor-associated macrophages (MФs) are the prominent components in the stroma. They provide a favorable microenvironment for tumor cells by cross-talking with other stromal cells and thus promote tumor growth, progression, and metastasis. In MM, MФs could induce drug resistance by protecting tumor cells from chemotherapy-induced apoptosis, and microarray analysis has ranked the top 250 paired genes including B-cell activating factor (BAFF) that may play a role in the MФs-MM cell interaction. ${ }^{10}$
Investigators have reported that myeloma cells express transmembrane activator and calcium-modulator and cyclophilin ligand interactor (TACI) and B-cell maturation antigen (BCMA), two genes coding for receptors of BAFF (also known as Blys). ${ }^{11}$ BAFF, a member of the tumor necrosis factor (TNF) family, was identified as a key factor in the normal B-cell biology. It also enhances the survival of various $B$ lymphocyte malignancies, including $\mathrm{MM} .^{12-14}$ It can act as a membranebound or proteolytically cleaved soluble form displaying typical features of type II transmembrane protein. ${ }^{15}$ It is expressed predominantly by stromal compartment including osteoclast, MФs, dendritic cells, and some T cells. ${ }^{16}$ Some studies have found that the tumor microenvironment secretes BAFF. ${ }^{17}$

Therefore, we choose to investigate the significance of BAFF in MФ-mediated MM bort resistance. We showed that primary myeloma cells and MM cell lines expressed BCMA and TACl heterogeneously. The expression of BAFF in MФs increased compared with monocytes. The BAFF-neutralizing antibody or knockdown of BAFF further attenuated the MФinduced bort resistance of MM cells. Thus, we try here to define a key role of BAFF, which is essential for MФ-mediated bort resistance of MM cells.

\section{Results}

Expression of BAFF and its receptors detected in MM cells. Our study first detected the expression of messenger RNA of BAFF and its three receptors, BCMA, TACl, and $B A F F-R$, from seven patients with $M M$ and in six MM cell lines

\footnotetext{
${ }^{1}$ Bone Marrow Transplantation Center, The First Affiliated Hospital, School of Medicine, Zhejiang University, Hangzhou, Zhejiang, China and ${ }^{2}$ Department of Cancer Biology, Lerner Research Institute, Cleveland Clinic, Cleveland, OH, USA

*Corresponding author: Z Cai, Bone Marrow Transplantation Center, The First Affiliated Hospital, School of Medicine, Zhejiang University, No. 79, Qingchun Rd. Hangzhou, Zhejiang Province 310006, China. Tel/Fax: +86 571 87236706; E-mail: caiz@zju.edu.cn

${ }^{3}$ These authors contributed equally to this work.

Received 03.5.17; revised 10.9.17; accepted 11.9.17; Edited by H-U Simon
} 
a

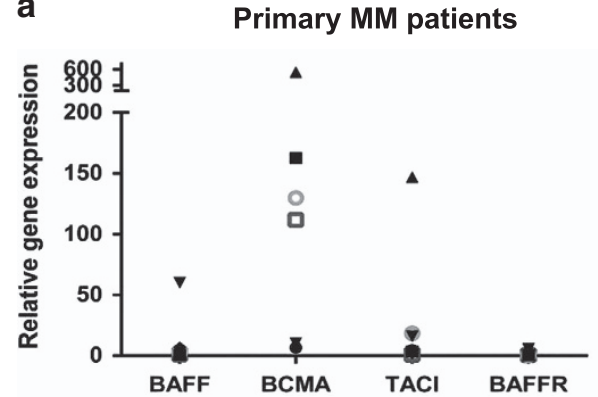

b
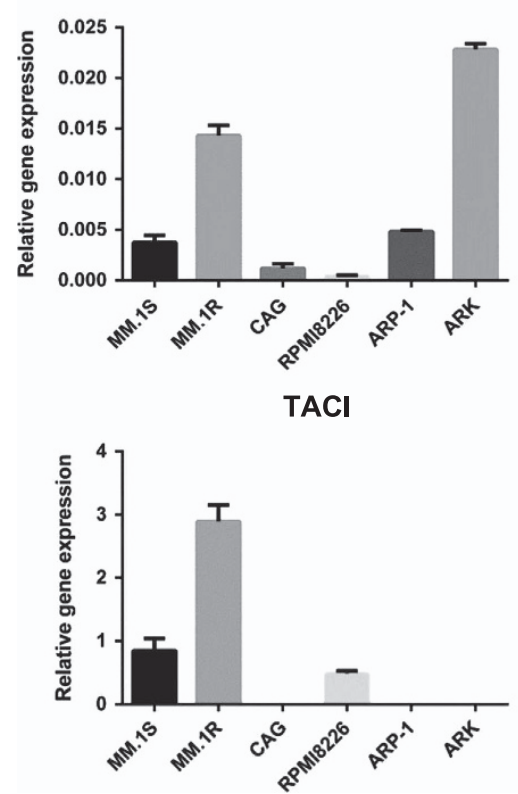

- Pt.1

- Pt.2

- Pt.3

- Pt.4

- Pt.5

- Pt.6

口 Pt.7
C ARP-1
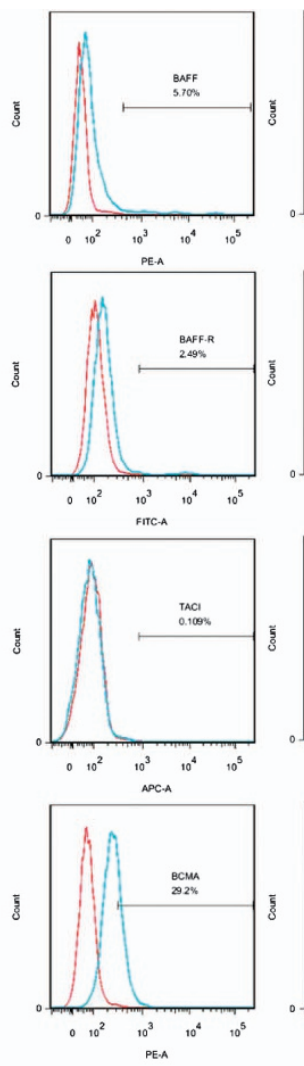

RPMI8226
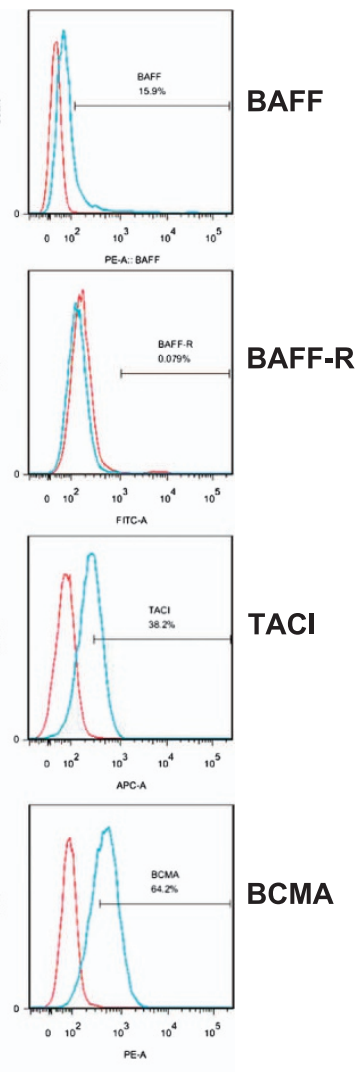

Figure 1 Expression of BAFF and BAFF-Rs in myeloma cells. The mRNA expression of BAFF and its receptors (BAFF-R, TACI, and BCMA) were detected using RT-PCR in seven CD138+ purified primary MM cell samples (a) and in six MM cell lines MM.1S, MM.1R, CAG, RPMI8226, ARP-1, and ARK (b). The cell surface expression of BAFF and its receptors in ARP-1 and RPMI8226 were detected by flow cytometry using anti-BAFF, anti-BAFF-R, anti-TACl, and anti-BCMA (blue lines) for 15 min at room temperature. Red lines indicate isotype Ig controls, done for each sample (c)

using qRT-PCR to evaluate the relevance of BAFF signaling in MM drug resistance. As shown in Figure 1a, tested primary MM cells express BAFF heterogeneously. Among the receptors of $B A F F$, the expression of $B C M A$ was significantly higher than that of TACl, with BAFF-R being the lowest: the maximum arbitrary units of BAFF, BCMA, TACI, and BAFF-R were $50,600,150$, and 5 , respectively. Similar results were observed in the six MM cell lines MM.1S, MM.1R, CAG, RPMI8226, ARP-1, and ARK (Figure 1b). Overall, the heterogeneous expression of BAFF and its receptors was consistent with that reported by $\mathrm{Yu}$-Tzu et al. ${ }^{18}$ Then, the surface expression of BAFF and its receptors in the two MM cell lines ARP-1 and RPMI8226 was examined using flow cytometry. Notably, ARP-1 and RPMI8226 expressed higher levels of BCMA and $\mathrm{TACl}$, lower levels of BAFF, and virtually undetectable BAFF-R, suggesting that altered expression of BAFF and its receptors might contribute to the process of MM cells resistant to apoptosis.

PBMC-induced MФs and expression of BAFF and its receptors in MФs. Macrophage colony-stimulating factor
(M-CSF) is a key homeostatic growth factor involved in the maintenance and differentiation of MФs. ${ }^{19}$ It is well established that M-CSF preferentially stimulated M2-like MФ phenotypes. $^{20-23}$ M2-like MФs had characteristics of spindle-like cells and relatively high expression of CD163 surface marker. ${ }^{24}$ In our study, MФs were harvested from peripheral blood monocytes (PBMCs) of healthy donors, which were incubated for 7 days with M-CSF. We observed that the cultured MФs were adherent to the six-well plates and had a spindle-like morphology (Figure 2a). The expression of CD68 and CD163 of MФs from different donors was $(24.6 \pm 0.39 \%)$ and $(78.4 \pm 0.67 \%)$, respectively. The flow cytometry analysis of the two CD molecules in MФs is shown in Figure $2 \mathrm{~b}$. Simultaneously, the expression of BAFF was measured during $M \Phi$ differentiation. As shown in Figure 2c, $M \Phi$ had increased expression of BAFF compared with monocytes $(P<0.05)$, and in monocyte-derived MФ, BAFF had relatively high expression whereas its receptors were barely detected by flow cytometry (Figure 2d). We also identified the expression of BAFF in CD68+ monocytes/ MФs from BM aspirates of patients with MM using 
a
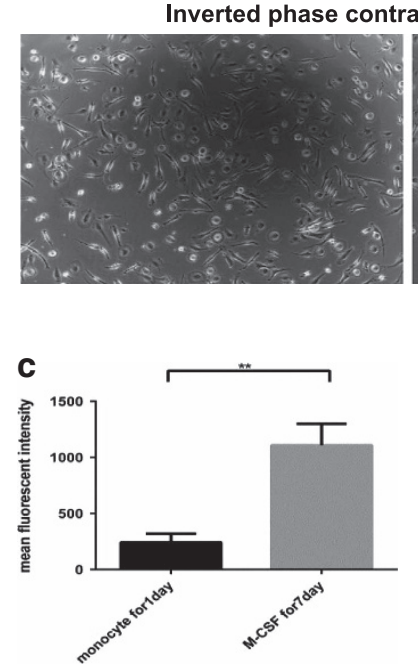

e
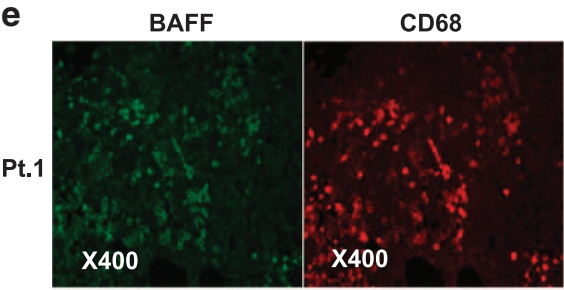

Pt.2

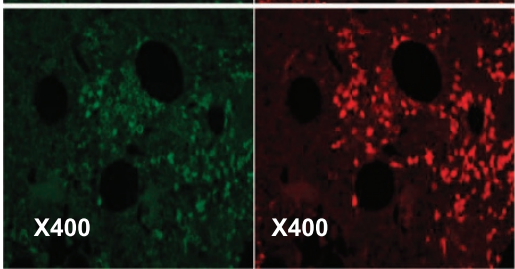

d

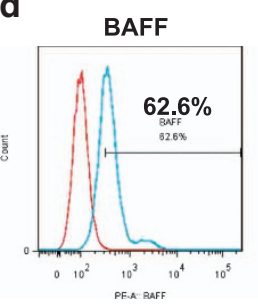

DAPI

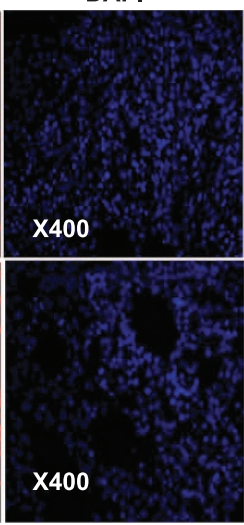

b

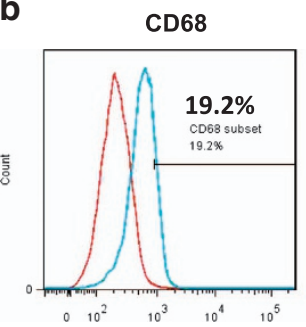

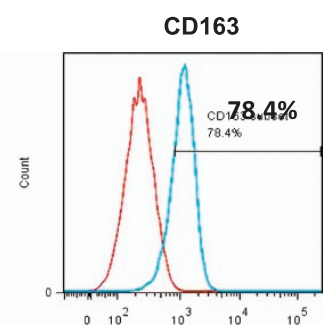

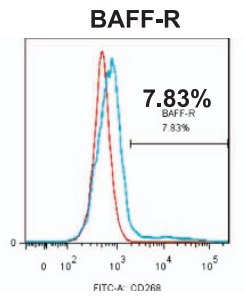

Merge
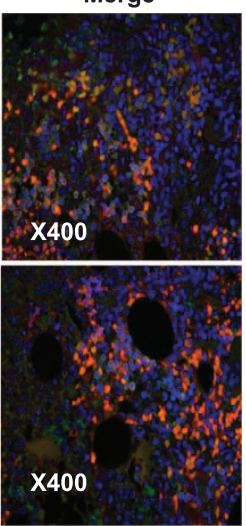
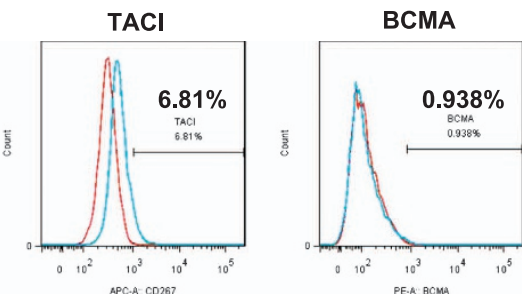

f

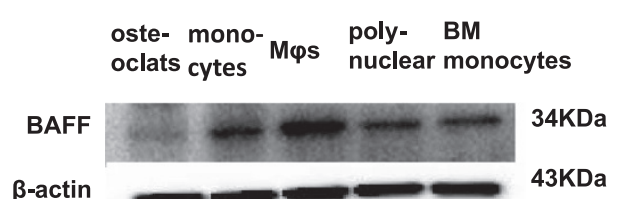

Figure 2 PBMC-induced MФs and the expression of BAFF and BAFF-Rs in MФs. Monocytes from healthy donors were cultured in RPMI-1640 supplemented with $10 \%$ FBS in the presence of M-CSF (10 ng/ml) for 7 days. (a) M2-type MФs adhered to the six-well plates and had a spindle-like morphology. (b) MФs were positive for CD68 and CD163 by flow cytometry analysis. (c) Monocytes and monocyte-induced MФs from seven blood donors were detected for the expression of BAFF by the flow cytometry analysis. Numbers represent the mean fluorescent intensity. (d) Cell surface expression of BAFF and its receptors in MФs were detected by flow cytometry. (e) Expression of BAFF on primary MФs from BM aspirates of patients with MM $(n=2)$ were detected using immunofluorescence. (f) Expression of BAFF on monocyte-derived osteoclast, monocytes, MФs, polynuclear cells, bone marrow monocytes were detected by Western blot
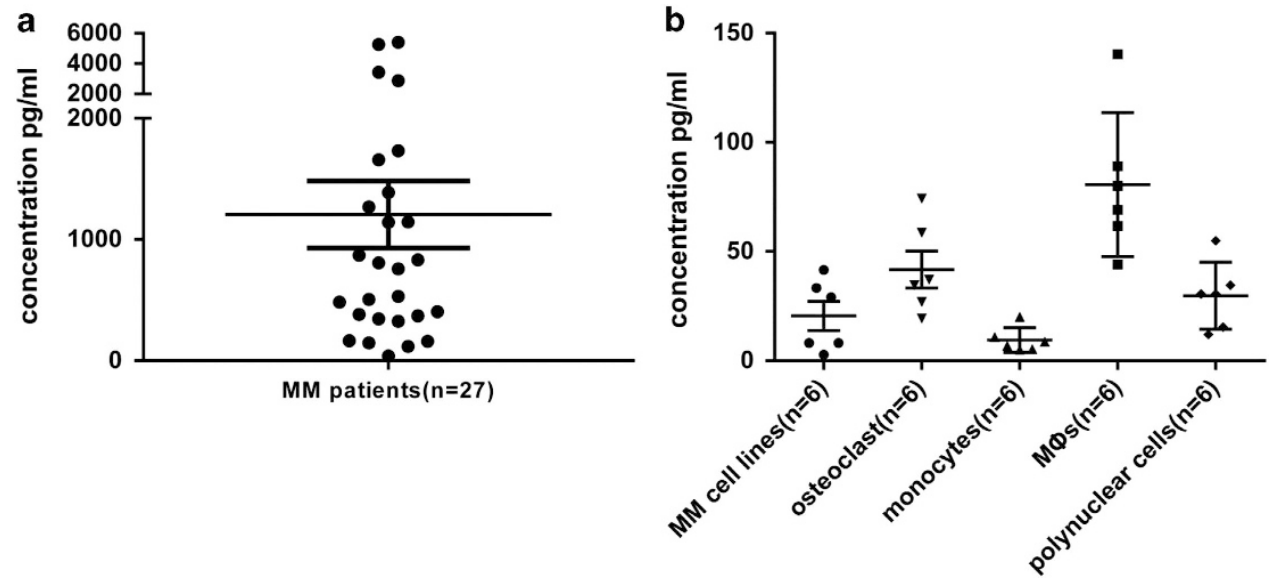

Figure 3 Expression of soluble BAFF. The supernatants of (a) BM of 27 patients with MM and (b) MM cell lines, osteoclasts, monocytes, MФs and polynuclear cells from six donors were collected for detecting BAFF using ELISA 


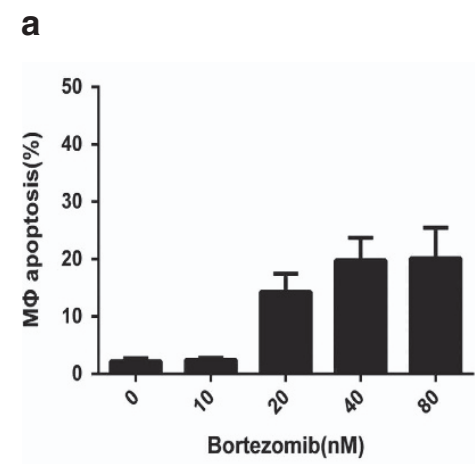

b
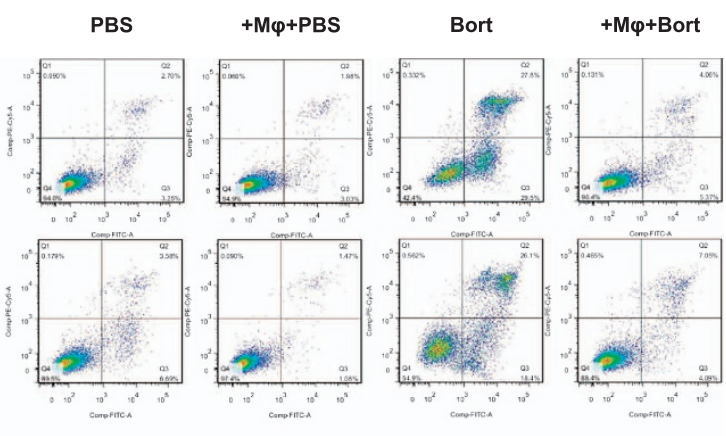

C

d
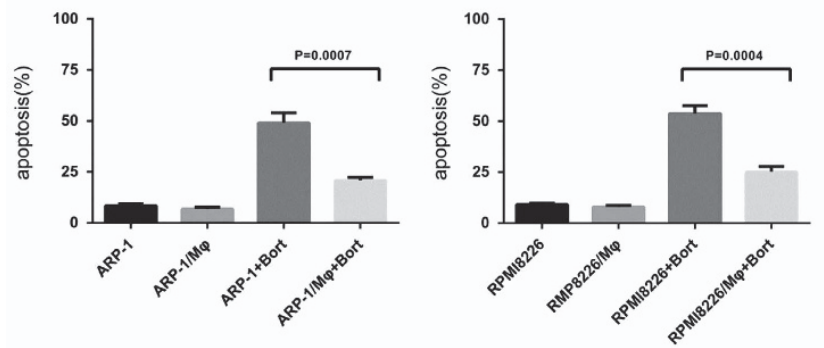

Annexin V
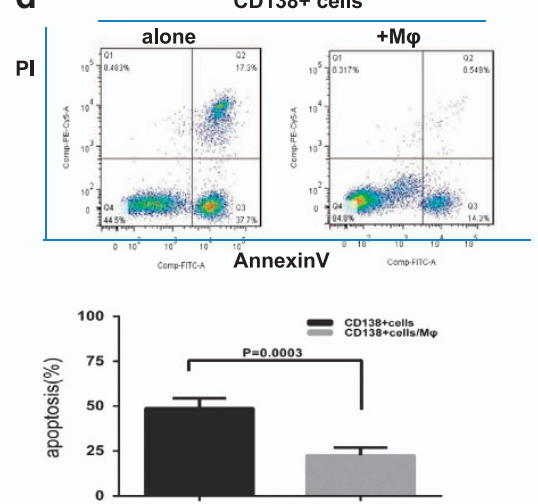

e
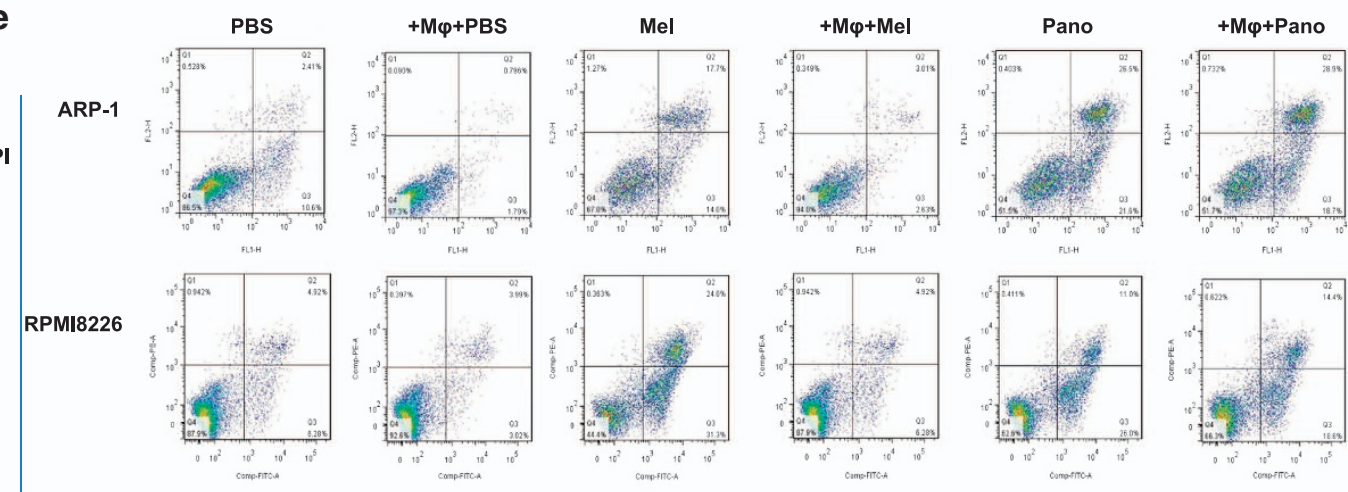

RPMI8226
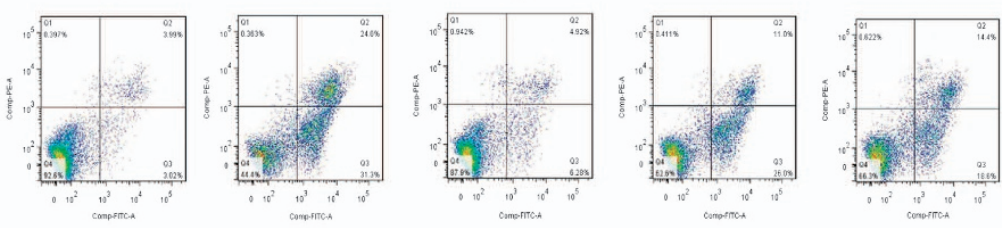

Annexin V
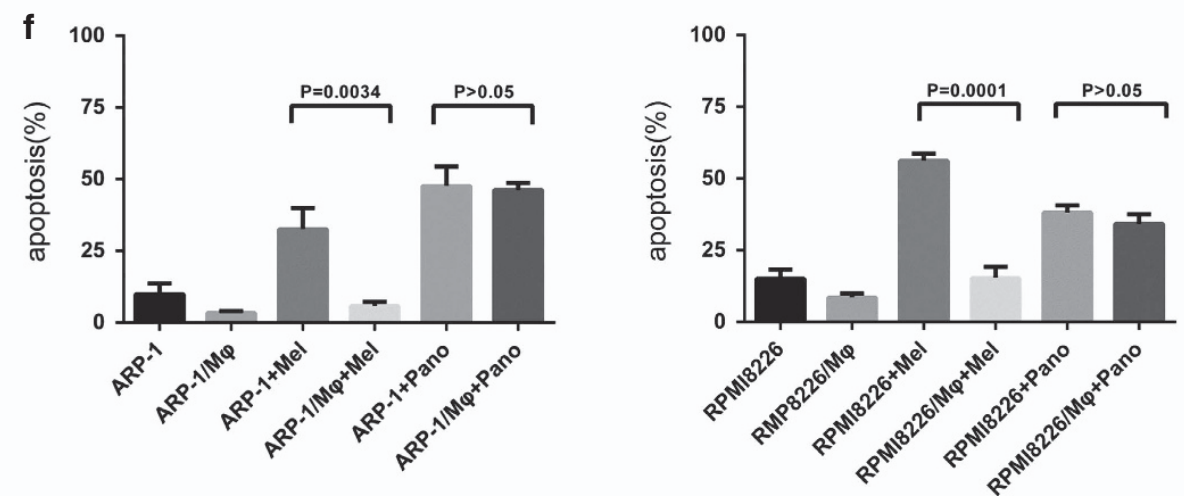


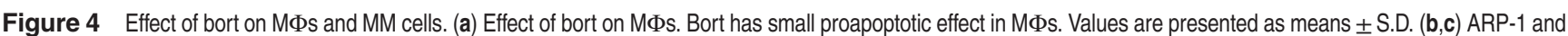
RPMI8226 cells were cultured alone or co-cultured with MФs in the absence or presence of bort ( 5 and $10 \mathrm{nM}$ for ARP-1 cells and RPMI8226, respectively; $24 \mathrm{~h}$ ). Apoptosis was evaluated by flow cytometry with Annexin V/PI staining. (b) A representative result showing that MФs reduced the bort-induced apoptosis of ARP-1 and RPMI8226 cells. (c) The

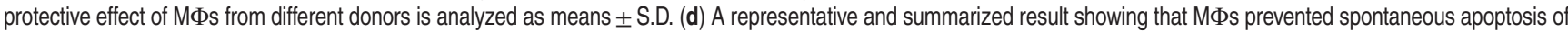
primary CD138+ plasma cells. Values are presented as means \pm S.D. (e,f) ARP-1 and RPMI8226 cells were cultured alone or co-cultured with MФs in the absence or presence of Mel (15 and $20 \mu \mathrm{M}$ for ARP-1 cells and RPMI8226, respectively; $24 \mathrm{~h}$ ) or Pano (250 and $300 \mathrm{nM}$ for ARP-1 cells and RPMI8226, respectively; $24 \mathrm{~h}$ ). Apoptosis was evaluated by flow cytometry with Annexin V/PI staining. (e) A representative result showing that MФs reduced apoptosis of ARP-1 and RPMI8226 cells from melphalan rather than panobinostat. (f) The protective effect of MФs from different donors is analyzed as means \pm S.D.

immunofluorescence (Figure 2e). Moreaux et al. ${ }^{17}$ had pointed out BAFF were mainly expressed by osteoclasts and BMSCs in the bone microenvironment. Concerning the induction of $M \Phi s$ in our experiment, we simultaneously detected BAFF expression in monocyte-derived osteoclast, monocytes, MФs, polynuclear cells, BM monocytes by western blot. Of major interest, MФs largely expressed BAFF while osteoclasts weekly expressed BAFF (Figure 2f).

BAFF production by BM cells, MM cell lines, and MФs. As BAFF is a secreted protein, we explored the presence of BAFF protein in the supernatants of BM of patients with MM, MM cell lines, and osteoclasts, monocytes, MФs, polynuclear cells from various donors. Using ELISA, median soluble BAFF levels were 1306.9, 20.5, 41.7, 9.60, 80.7, and $29.7 \mathrm{pg} /$ $\mathrm{ml}$ in culture supernatants of BM of patients with MM, MM cell lines, osteoclasts, monocytes, MФs and polynuclear cells, respectively, showing the presence of the soluble form of BAFF (Figures $3 a$ and b).

PBMC-induced MФs were insensitive to bort and protected MM cells from bort-induced apoptosis. Because BM microenvironment contributes to the drug resistance of plasma cells, ${ }^{25}$ we wondered whether MФs mediated the resistance of MM cells to bort. The role of PBMC-derived $M \Phi s$ in vitro was determined via bort-induced apoptosis of ARP-1, RPMI8226, and CD138+ plasma cells from patients with MM. We first investigated the direct function of bort on MФs. Bort (range 0-80 nM) had small effect in inducing apoptosis of MФs (Figure 4a). Besides, MФs co-cultured with ARP-1 (bort, $5 \mathrm{nM}$ ) and RPMI8226 (bort, $10 \mathrm{nM}$ ) significantly weakened bort-induced apoptosis (Figures $4 \mathrm{~b}$ and $\mathrm{c}$ ). Bort concentration was determined according to the inhibitory concentration $50 \%$ of ARP-1 and RPMI8226 (data not shown). Moreover, CD138+ plasma cells from four patients with MM, which were susceptible to spontaneous apoptosis in vitro, were obviously protected by MФs (Figure 4d) when co-cultured with MФs, suggesting the protective effect of MФs. We also extended our study to the conventional agent melphalan (Mel) and histone deacetylase inhibitors (HDACi) panobinostat (Pano). The results showed that MФs protected ARP-1 and RPMI8226 from Mel-induced apoptosis under the co-culture condition. However, the protective effect was no longer observed when tested MM cells were treated with Pano (Figures $4 \mathrm{e}$ and $\mathrm{f}$ ).

BAFF was indispensable for MФ-mediated bort resistance of MM cells. A previous study provided the gene expression profile data of MM cells and MФs cultured alone or co-cultured, 250 paired genes were differentially expressed. ${ }^{10}$ Based on these data, we hypothesized that BAFF (on MФs) and its receptors (on MM cells) played a role in the $M \Phi$-mediated bort resistance of MM cells. MФs were cultured alone or co-cultured with MM cell lines for $24 \mathrm{~h}$, the suspended MM cells were removed and washed with phosphate-buffered saline (PBS) to obtain pure MФs, we found $M \Phi s$ in co-cultured condition led to an increased expression of BAFF as detected by western blot (Figure 5a). We interrupted the interaction between BAFF and its receptors using BAFF-neutralizing antibody, and then examined $M \Phi$-mediated protection. As shown in Figures $5 \mathrm{~b}$ and $\mathrm{c}$, the BAFF-neutralizing antibody, but not control IgG2B, repressed the MФ-mediated bort resistance of MM cells (ARP-1 and RPMI8226) and partially restored MM cell sensitivity to bort in direct co-culture with MФs. Similar findings are shown in Figure $5 d$ in which BAFF-neutralizing antibody attenuated the $\mathrm{M} \Phi$-mediated spontaneous apoptosis of CD138+ plasma cells compared with control IgG2B.We also examined MФ-mediated MM drug resistance in BAFFknocked down MФs. MФs were transduced with siRNAs targeting BAFF (TNSF13B-Homo-296, TNSF13B-Homo-700, and TNSF13B-Homo-973) or control nontargeting siRNA. The transduction of BAFF-specific siRNAs reduced protein levels of BAFF in MФs differently (Figure 5e). TNSF13BHomo-973 conferred that significant BAFF knockdown resulted in the reduced ability of MФs in protecting MM cells (ARP-1 and RPMI8226) from bort-induced apoptosis (Figures $5 f$ and $\mathrm{g}$; compared with sictl-MФs). Thus, our findings indicated that BAFF (on MФs) and its receptors (on MM cells) played a profound role in $M \Phi$-mediated bort resistance of MM cells. Similarly, BAFF-knocked down MФs were not protecting MM cells against Mel-induced apoptosis to a large extent (Supplementary Figures $1 \mathrm{~A}$ and B).

Effect of BAFF on signaling pathway in co-cultured MM cells. To learn if the intracellular survival signaling was stimulated by $\mathrm{M} \Phi / \mathrm{MM}$ co-culture that conferred bort resistance of MM cells in vitro, first, apoptotic cell characteristics of PARP and caspase- 3 cleavage were detected using western blot in MM cells under co-culture conditions either with BAFFneutralizing antibody or control lgG2B in the presence of bort. The result showed that in ARP-1 cells co-cultured with MФs, bort-induced PARP and caspase-3 cleavage had high repression (Figure 6a). However, neutralization of BAFF under co-culture conditions or ARP-1 cells co-cultured with BAFF-knocked MФs (Supplementary Figure 2A) had moderate elevation of these apoptotic proteins (Figure 6b). Next, the possible signaling mediators were examined in MM cells. 
a

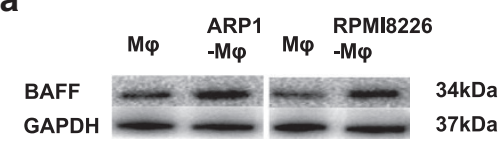

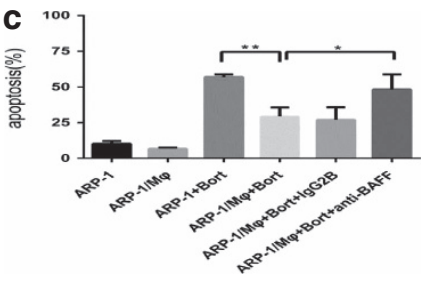

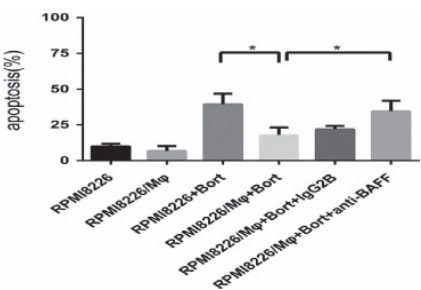

b

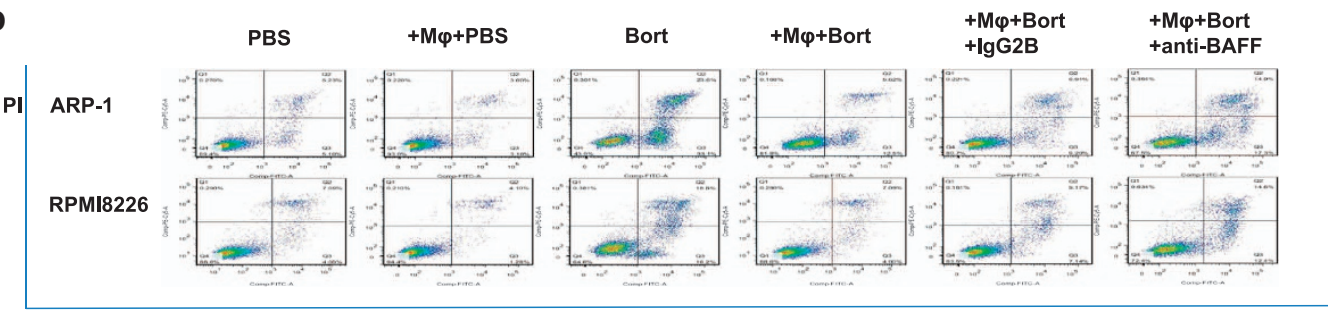

Annexin V

d
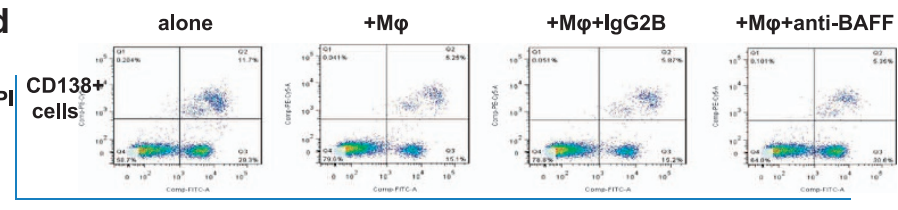

Annexin V

e

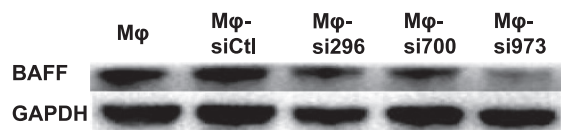

$34 \mathrm{kDa}$

$37 \mathrm{kDa}$

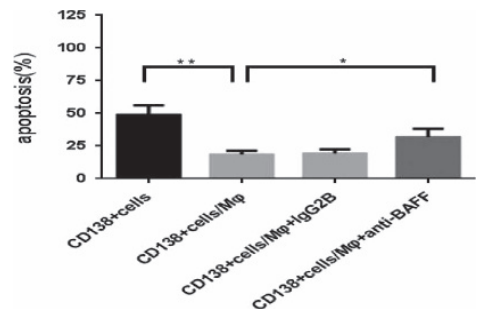

f

ARP-1 Bort
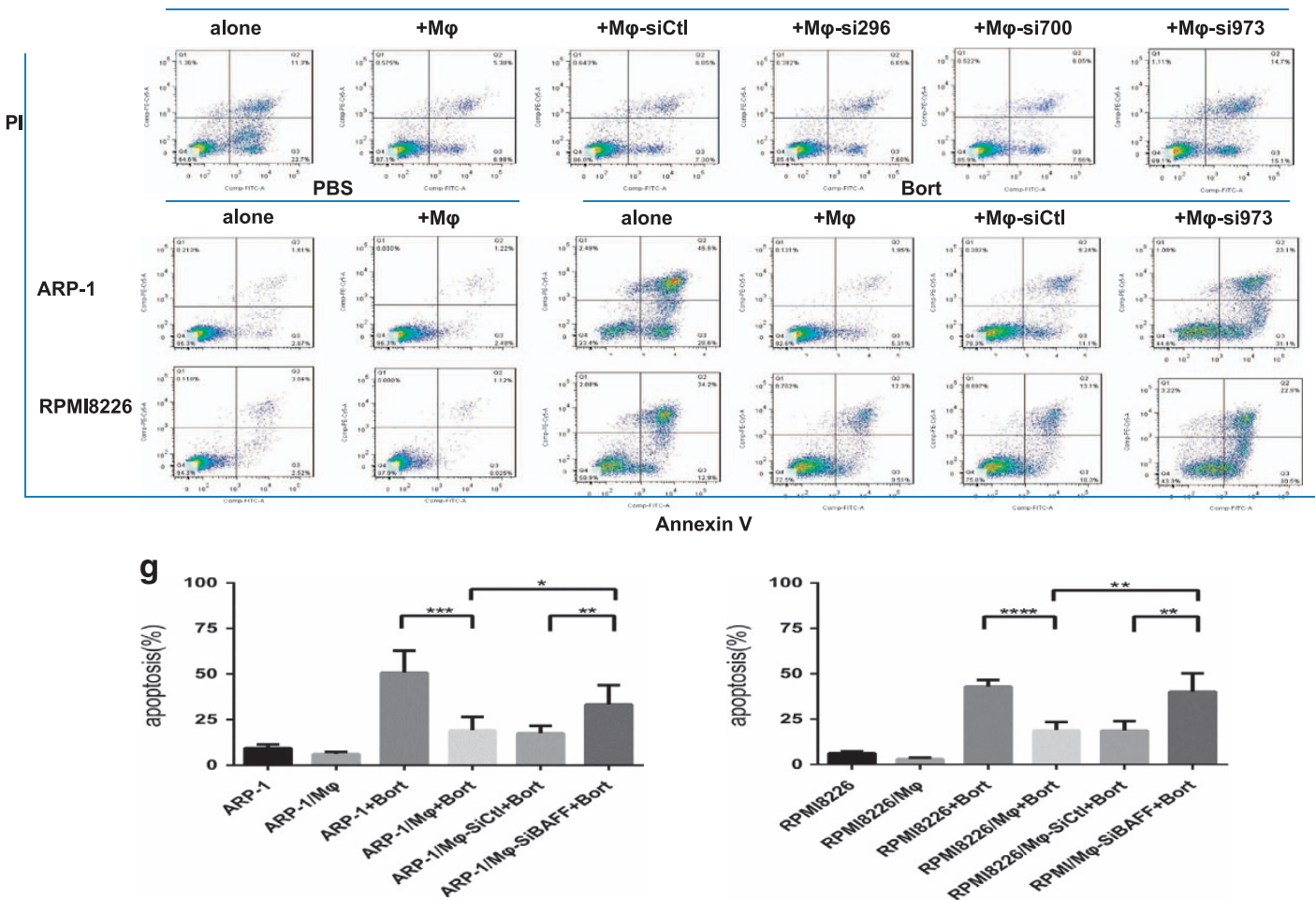
Figure 5 BAFF is indispensable for MФ-mediated MM bort resistance. (a) Lysates from MФs either cultured alone or co-cultured with MM cell lines (ARP-1 and RPMI8226) were detected for the expression of BAFF protein using an anti-BAFF antibody by Western blot, with GAPDH used as a loading control. Apoptosis was evaluated by flow cytometry with Annexin V-FITC/ propidium iodide staining. (b) A representative result showing the percentage of bort-induced apoptotic MM cells ( $5 \mathrm{nM}$ ARP-1 and $10 \mathrm{nM}$

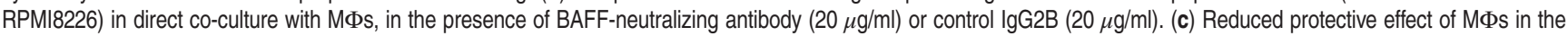
presence of BAFF-neutralizing antibody is analyzed as means \pm S.D. (d) Results showing BAFF-neutralizing antibody attenuated the effect of MФs in protecting primary CD138+ plasma cells from spontaneous apoptosis. Values are presented as means \pm S.D. (e) M $\Phi$ s treated with BAFF-specific siRNAs showed a diverse reduction of BAFF protein compared with nontargeting siRNA (control) at $72 \mathrm{~h}$ using Western blot, with GAPDH as a loading control. (f) A representative result showing bort-induced apoptosis on ARP-1

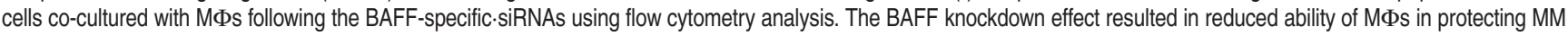
cells. (g) Result showing percentage of bort-induced apoptotic MM cells (ARP-1 and RPMI8226) in direct co-culture with BAFF-knocked down MФs. Values are presented as means \pm S.D. ${ }^{\star} P<0.05,{ }^{* \star} P<0.01,{ }^{* \star \star} P<0.001,{ }^{* \star *} p<0.0001$

MФs were found to activate phosphorylated Akt, Erk1/2 kinase, and Src in ARP-1 cells treated with bort, which had lower levels of $p$-Akt, $p$-Erk1/2, and $p$-Src when treated with BAFF-neutralizing antibody. Similar findings were also observed from BAFF-knocked-down MФs (Supplementary Figure 2B) co-cultured with ARP-1 cells, suggesting that BAFF played a role in $M \Phi$-mediated bort resistance through Akt, Erk1/2 and Src pathway activation (Figure 6c).

A previous study explained that the BAFF promoter was an essential activation element of nuclear factor kappa B (NF- $k \mathrm{~B}$ ) transcription triggered by the adhesion of $\mathrm{MM}$ cells to BMSCs. ${ }^{26} \mathrm{NF}-\kappa \mathrm{B} 2$ activation relies on both NIK (NF- $\kappa \mathrm{B}-$ inducing kinase) and its downstream kinase IKKa with the persistent degradation of TRAF3 and increased expression of NIK. It also involves the processing of p100 to p52 and translocation of p52 to the nuclear fraction. ${ }^{27-29}$ Our present study found that BAFF-knocked-down MФs (Supplementary Figure $2 \mathrm{C}$ ) co-cultured with ARP-1 cells partly repressed the activation of NF-kB2 (Figure 6d). We also observed the degradation and phosphorylation of the inhibitor of kappa $\mathrm{Ba}$ $\left(I_{\kappa} \mathrm{B} a\right)$ and p65 translocation to the nucleus, implying the activation of the canonical pathway of NF- $\kappa \mathrm{B}$ (Figures $6 \mathrm{~d}$ and e). The signaling pathway was not activated further by coculture with BAFF-knocked-down MФs (Figures 6d and e). These results indicated that BAFF-induced bort resistance of MM cells co-cultured with MФs was conducted via activation of both classical and alternative NF-kB pathways.

MФ-mediated bort resistance of MM cells in vivo. The human MM-NOD-SCID mouse model was used to evaluate whether in vivo environment corresponded to in vitro findings that MФs could protect myeloma cells from bort-induced apoptosis. ARP-1 cells and ARP-1 mixed with monocytes were subcutaneously injected into the flanks of NOD-SCID mice. We enumerated $M \Phi$ infiltration in a tumor by immunohistochemical analysis using the anti-human CD68 antibody (Figure 7a). Mice bearing ARP-1 tumor alone or ARP-1 tumor mixed with human MФs were treated with bort every 3 days to assess bort-induced cell death in vivo. After treatment for 2 consecutive weeks, the mice were killed and the tumors were harvested. Then, the apoptotic cells of tumor masses were detected by immunohistochemistry staining with the anti-cPARP antibody (Figure $7 \mathrm{~b}$ ) and flow cytometry analyses for Annexin V-FITC/propidium iodide(PI)-positive cells (Figure 7c). The tumor generated by ARP-1 alone cells had more positive staining of cPARP and Annexin V/PI. These results supported that MФs could protect MM cells in the presence of bort in vivo. Consistently, this study found that mice bearing ARP-1/MФ cells had a larger tumor volume in the presence and absence of bort (Figure 7d), indicating that MФs manifested compromised therapeutic effects of bort (a 2-week treatment schedule) on tumors. Furthermore, we observed in vivo tumors from BAFF-neutralizing antibodytreated ARP-1/MФ mice, which showed small-sized volumes compared with control IgG2B-treated group with bort as described earlier (Figures $7 e$ and f). These results are correspondent with in vitro studies showing that BAFF was involved in MФ-mediated bort resistance of MM cells.

\section{Discussion}

Mechanisms of bort resistance in MM have been implicated in both intrinsic changes, including MM cells and their subclone heterogeneity, and the protective efficacy of BMSCs. ${ }^{6,7,30} \mathrm{We}$ demonstrated that primary CD138+ plasma cells from patients with MM underwent spontaneous apoptosis in vitro, suggesting that plasma cells in vivo reacquired susceptibility when separated from the BM microenvironment in vitro. MФs, a type of BMSCs, were heavily infiltrated in the myeloma microenvironment. $^{31,32}$ The specific roles of MФs in the pathogenesis of tumors are now being delineated. For example, a previous study demonstrated that $M \Phi$ s exhibited tumor-promoting activities via increasing angiogenesis and metastasis, and suppressing anti-tumor immunity. ${ }^{33,34}$ In particular MФs could mediate multidrug resistance of MM cells to both conventional and novel chemotherapy drugs. ${ }^{10}$ Our present study demonstrated that PBMC-induced MФs were resistant to bort in vitro and protected primary MM cells and $\mathrm{MM}$ cell lines from spontaneous and bort-induced apoptosis. Of note, we found MФs were not able to reduce panobinostat-induced MM apoptosis. Histone deacetylase inhibitor panobinostat has emerged as a particular treatment option for MM. Previous studies showed the anti-myeloma activity of panobinostat was related to changes in intracellular modifications that influence the interaction of MM cells with the microenvironment. ${ }^{35}$ The positive alteration of panobinostat to MM microenvionment which comprises extracellular matrix and the BMSC may account for the disappeared protective effect of MФs. We thus assume defining the mechanisms whereby MФs protected MM cells could potentially identify a promising target for MM therapy.

BAFF, a member of the TNF superfamily, was identified as a humoral factor highly expressed in the BM microenvironment of MM. Studies showed that BMSCs were the main product source of BAFF. ${ }^{13,18}$ Because myeloid lineage cell monocytes including MФs, dendritic cells were originally found to express 


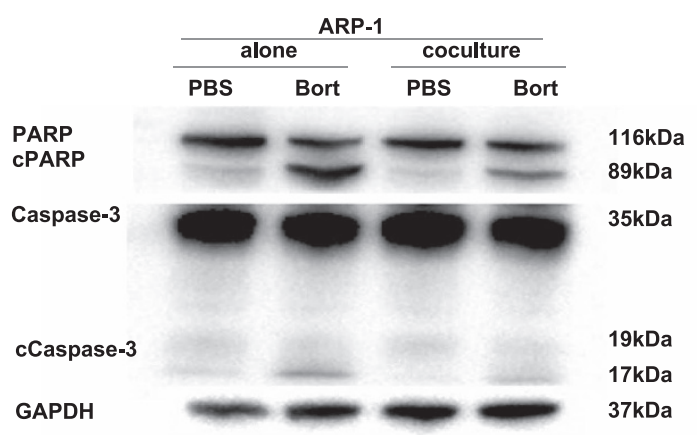

b

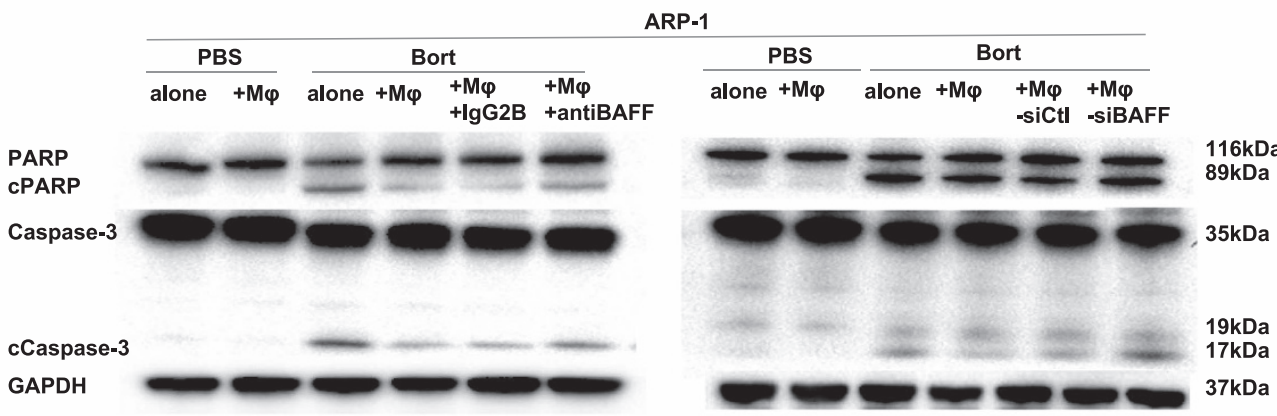

C

\begin{tabular}{|c|c|c|c|c|c|c|c|c|c|}
\hline \multirow[b]{2}{*}{ PBS } & \multirow{2}{*}{\multicolumn{6}{|c|}{ PRS }} & \multirow{2}{*}{\multicolumn{3}{|c|}{ Bort }} \\
\hline & & & ort & & & & & & \\
\hline$+M \varphi$ & alone & $+M \varphi$ & $\begin{array}{l}+\mathrm{M} \varphi \\
+\lg G 2 B\end{array}$ & $\begin{array}{l}+\mathrm{M} \varphi \\
\text { +antiBAFF }\end{array}$ & alone & $+M \varphi$ & alone & $+\mathrm{M} \varphi$ & $\begin{array}{l}+\mathrm{M} \varphi \\
- \text { siCtl }\end{array}$ \\
\hline
\end{tabular}
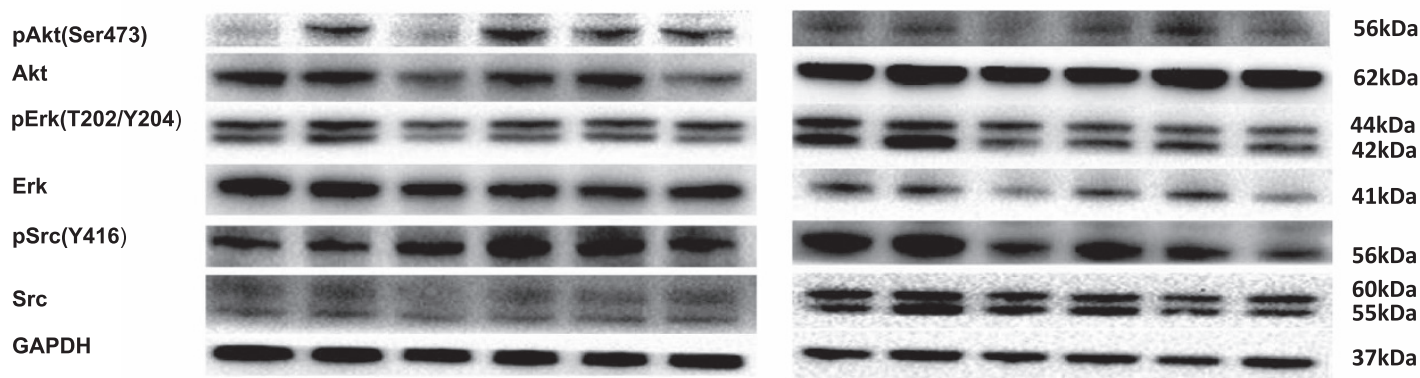

d

TRAF3
NIK
IKKa
pNFKBp100
(Ser866/870)
IKB $\alpha$
plkB $\alpha$
(Ser32)
GAPDH

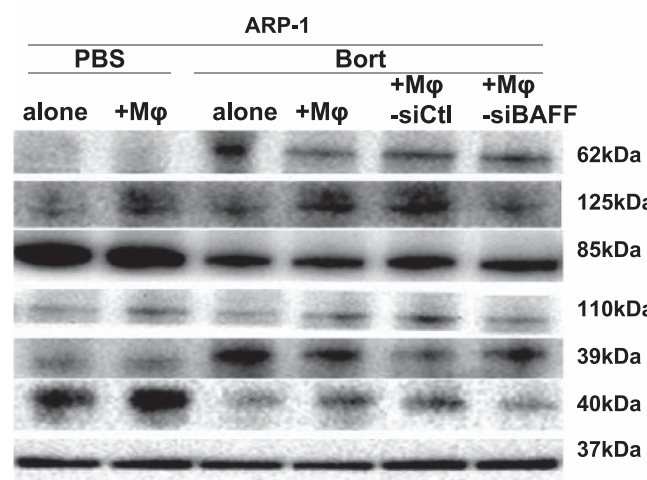

e

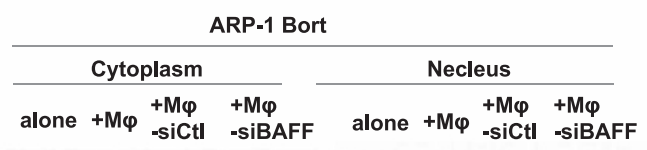

Figure 6 Involvement of BAFF in M $\Phi$-mediated protection of ARP-1 cells. Western blot analyses showed that (a) ARP-1 cells cultured alone or co-cultured in direct contact with MФs were detected for activation and cleavage of PARP and caspase-3, either PBS-treated or bort-treated (5 nM, $24 \mathrm{~h})$. (b) ARP-1 cells cultured alone or co-cultured in direct contact with MФs in the presence of BAFF-neutralizing antibody or control lgG2B and ARP-1 cells cultured alone or co-cultured in direct contact with sictl-MФs or siBAFFMФs were detected for activation and cleavage of PARP and caspase-3, either PBS-treated or bort-treated ( $5 \mathrm{nM}, 24 \mathrm{~h}$ ). (c) Expression of pAkt (Ser473), Akt, pErk1/2 (T202/ Y204), Erk1/2, pSrc (Y416), Src, and GAPDH in ARP-1 cells cultured alone or directly co-cultured with MФs in the presence of BAFF-neutralizing antibody or control lgG2B and in ARP-1 cells cultured alone or directly co-cultured with sictl-MФs or siBAFF-MФs, either PBS-treated or bort-treated ( $5 \mathrm{nM}, 24 \mathrm{~h}$ ). (d) Expression of TRAF3, NIK, IKK $\alpha$, IKB $\alpha$, and

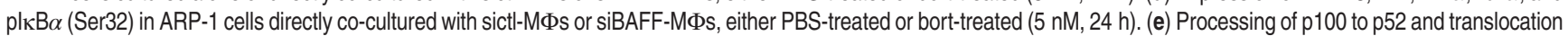

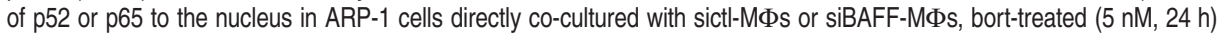


a

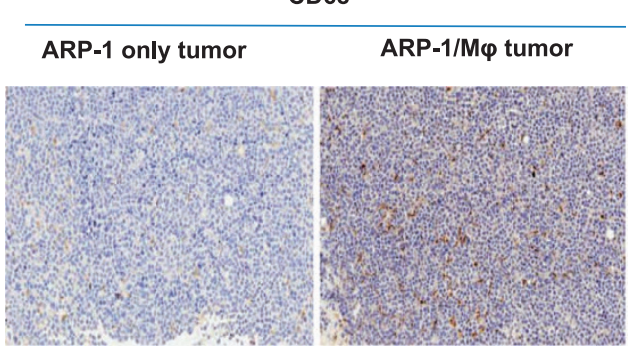

b

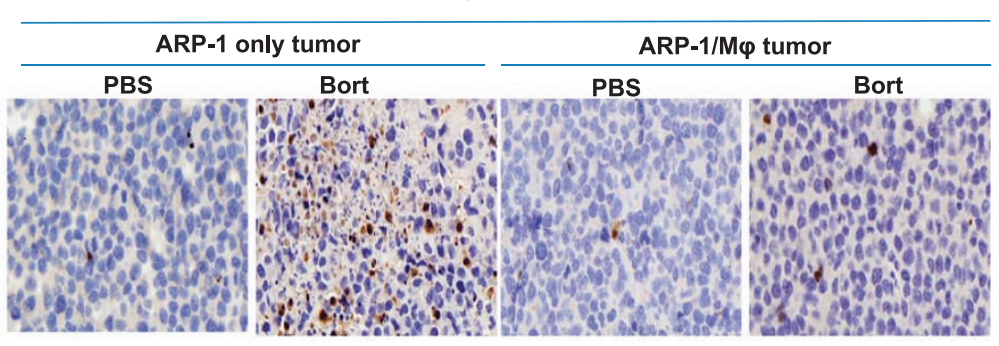

C

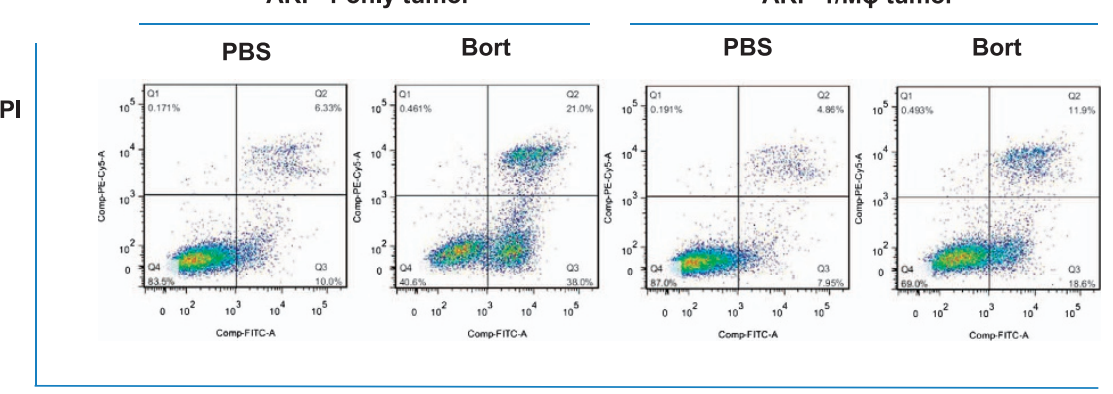

ARP-1/M $\varphi$ tumor

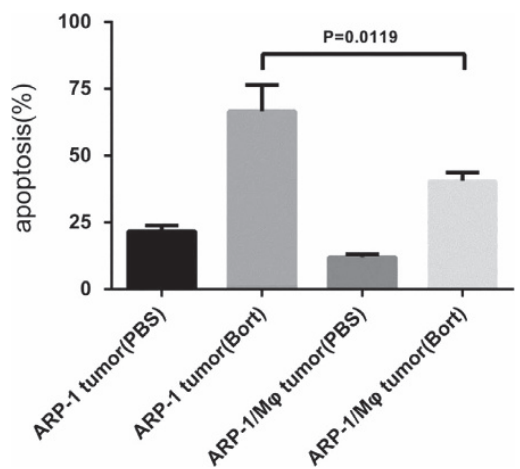

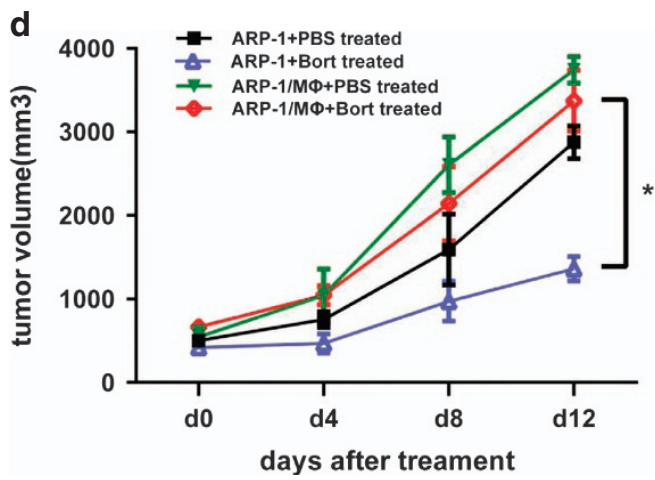

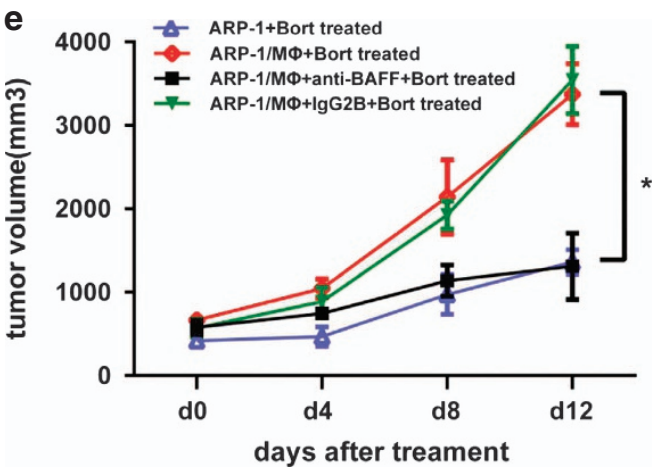

f

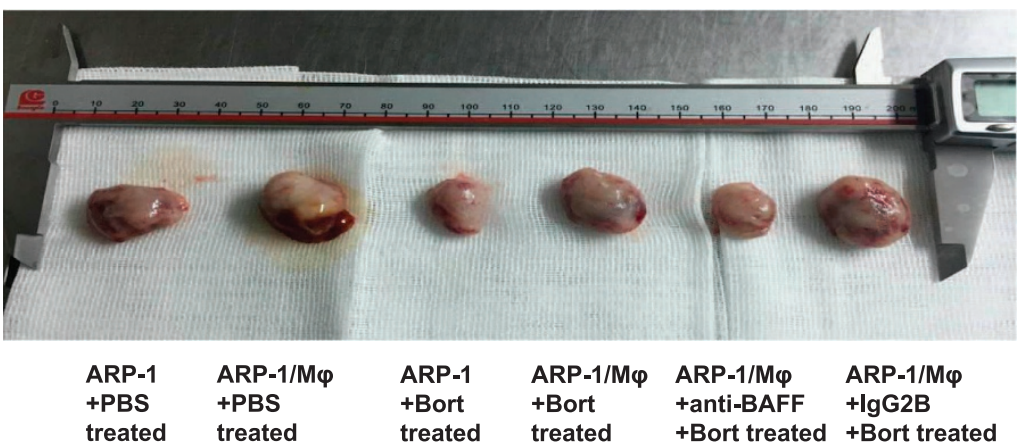

Figure 7 In vivo effect of MФ-mediated MM bort resistance in the myeloma NOD-SCID mouse model. (a) Human M $\Phi$ infiltration in tumors from ARP-1 cells (ARP-1 only tumor) and ARP-1/monocytes (ARP-1/M $\Phi$ tumor) was detected by immunohistochemistry staining of CD68. Tumors from myeloma-bearing NOD-SCID mice treated with bort ( $2 \mu \mathrm{g}$ /mouse every 3 days for 2 consecutive weeks) or PBS (served as controls) were detected for apoptotic cells (b) using immunohistochemistry staining with anti-cPARP antibody and (c) flow cytometry staining with Annexin V-FITC/propidium iodide. (d) Tumor burdens under different groups were detected as tumor volume. (e) Tumor volume of bort-treated myeloma-bearing NOD-SCID mice ( $n=5 /$ group) treated with BAFF-neutralizing antibody ( $100 \mathrm{mg} / \mathrm{mouse}$, every 3 days for 2 consecutive weeks) or control lgG2B. ${ }^{\star} P<0.05$. (f) Tumor volume in different treatment groups 
BAFF, ${ }^{36,37}$ and MФs are important components of the BMSCs of $\mathrm{MM}$ that support plasma cell survival and induce chemotherapy resistance. ${ }^{32}$ Therefore, we anticipated a role of BAFF in the adhesion of MФs and MM cells. Our study demonstrated that MФs had increased expression of BAFF compared with monocytes, and the secretion level of BAFF in MФs was higher than that in MM cell lines, which was in accordance with previous reports that BAFF signaling acted mainly through a paracrine system rather than an autocrine mechanism. ${ }^{13,17}$ We also demonstrated that PBMC-induced MФs could protect MM cells from both spontaneous and bortinduced apoptosis. When we utilized BAFF-neutralizing antibody under co-culture conditions or knocked-down expression of BAFF on MФs, MM cell apoptosis significantly increased, implying that BAFF on MФs could contribute to their ability to confer MM cells with resistance to bort. Therefore, strategies that interfere with BAFF only might be useful to attenuate the resistance of MM cells to bort in vivo.

Our data showed that MФs mediated bort resistance of MM cells, suggesting that the mechanism might be associated with the survival signaling pathway activation of MM cells. Indeed, the present study detected the activation of phosphorylated Akt, Erk1/2 kinase and Src in MM cell lines following co-culture with MФs, all of which were essential to promote MM cell growth and drug resistance. We also identified that the survival pathway activation was attenuated when the expression of BAFF was interrupted in the co-culture system. Thus, it is plausible that BAFF supports the development of bort resistance of MM cells.

BAFF triggers its functions through NF- $k \mathrm{~B}$ activation, and two main pathways (canonical and alternative) modulate the activity of NF- $\kappa B^{38}$ The canonical pathway activation results from the degradation of $I_{\kappa} \mathrm{B} a$ and thus leads to the nuclear translocation of p65. Activation of the alternative pathway results from IKKa-dependent p100 phosphorylation and nuclear translocation of p52. The present study showed that BAFF-induced bort resistance of MM cells/MФs took place via activation of both classical and alternative NF- $\kappa$ B pathways. This is similar to the interaction between BAFF and its receptors on lymphoma and normal $B$ cells, which promotes $\mathrm{I}_{\kappa} \mathrm{B} a$ degradation and processes of NF- $\kappa \mathrm{B} 2$, respectively. ${ }^{39-42}$

Monoclonal antibody-based therapies existed great promise in MM. ${ }^{43}$ Recently, tabalumab (LY2127399), with neutralizing activity against BAFF, was found to be well tolerated and showed a better response when combined with bort in relapsed and refractory patients with $M M{ }^{13}{ }^{13}$ Indeed there are other molecules such as APRIL, BAFF-R,BCMA, and TACI related to BAFF signaling pathway, and particularly APRIL is evidenced playing significant role in MM cell survival and targeting BCMA is in development. Despite these complexities, it remains crucial to examine whether targeting BAFF alone in $\mathrm{MM}$ is sufficient, and the overall results highlighted a functional role of BAFF in MФ-mediated bort resistance of MM cells, providing a basis for the molecular- and immunetargeted therapeutic approach. Taken together, BAFF signaling might serve as an interesting target for MM treatment.

\section{Materials and Methods}

Cell preparation and culture. Human MM cell lines MM.1S, MM.1R, CAG, RPMI8226, ARP-1, and ARK were generously provided by Dr. Qing Yi (Department of Cancer Biology, Lerner Research Institute, Cleveland Clinic, Cleveland, $\mathrm{OH}$, USA). All MM cell lines expressed CD138 (>97\% of cells) as detected by the flow cytometric analysis. BM samples were obtained from patients with MM after informed consent from all patients and the approval of the Ethics Committee of the First Affiliated Hospital, College of Medicine, Zhejiang University. Freshly isolated CD138+ cells were purified by positive selection using CD138 microbeads (Miltenyi Biotech, San Diego, CA, USA). All MM cell lines and primary MM cells were maintained in the RPMI-1640 medium containing L-glutamine (Corning Cellgro, Tewksbury, MA, USA), supplemented with $10 \%$ fetal bovine serum (FBS; Thermo Fisher Scientific, Gibco, Waltham, MA, USA), at $37^{\circ} \mathrm{C}$ and in $5 \% \mathrm{CO}_{2}$ in air.

PBMCs were obtained from healthy donors after informed consent. Human MФs were generated from PBMCs in vitro as described in a previous study. ${ }^{31}$ Monocytes were cultured at 12-18 million per six-well plates in the RPMI-1640 medium. After 1$2 \mathrm{~h}$ of incubation, nonadherent cells were removed and adherent monocytes were cultured in RPMI- 1640 containing 10\% FBS and M-CSF ( $10 \mathrm{mg} / \mathrm{ml}$; R\&D systems, Minneapolis, MN, USA) for 7 days to transform into MФs. Before use, MФs were phenotyped by morphological and detected for classic molecular markers CD68 and CD163.

The MM cells were directly added to MФs at a 1: 1 ratio and co-cultured for $24 \mathrm{~h}$ with bort to evaluate the effect of MФs on bort-induced apoptosis in MM cells. Suspended MM cells were obtained by collecting the supernatant and then tested via functional assays.

Reagents. Primary antibodies against caspase-3, poly(ADP-ribose) polymerase 1 (PARP-1), Akt, phospho-Akt (Ser473), phospho-Akt (Ser308), Src, pSrc (Y416), Erk, pErk (T202/204), and CD68 were purchased from Cell Signaling Technology (Danvers, MA, USA). Anti-CD138 was from Abcam (Cambridge, UK). APC antihuman CD68, PE mouse anti-human CD163, PE mouse anti-human BAFF, APC rat anti-human CD267 (TACl), PE anti-human CD269 (BCMA), and fluorescein isothiocyanate (FITC) mouse anti-human CD268 (BAFF receptor, or BAFF-R) were all obtained from Biolegend (San Diego, CA, USA). Primary antibodies including $\beta$ actin and glyceraldehyde-3-phosphate dehydrogenase (GAPDH) were obtained from Sigma-Aldrich (Billerica, MA, USA). Horseradish peroxidase (HRP)-conjugated anti-rabbit and anti-mouse antibodies were procured from Jackson ImmunoResearch Laboratories (Lancaster, PA, USA). Human BAFF antibody and mouse immunoglobulin G2b (IgG2B) isotype control were purchased from R\&D Systems.

RNA extraction and quantitative reverse transcriptasepolymerase chain reaction (qRT-PCR) analysis. The total RNA from MM cells was extracted using a Trizol reagent (Invitrogen, Carlsbad, CA, USA). Reverse transcription was performed using a High-Capacity cDNA Reverse Transcription Kit (Applied Biosystems, Waltham, MA, USA). qRT-PCR was performed using the iTaq universal SYBR Green Supermix (Bio-Rad, Hercules, CA, USA) with the Bio-Rad CFX96 real-time system, according to the manufacturer's instruction, and normalized to GAPDH RNA levels calculated by POWER values and plotted as relative quantification. Each sample was run in triplicate. Amplification primer sequences were as follows: human BAFF, 5'CGCGGGACTGAAAATCTTTG-3' and 5'-CACGCTTATTTCTGCTGTTCTGA-3'; human BCMA, 5'-TCCTCTAACATGTCAGCGTTATTGT- $3^{\prime}$ and $5^{\prime}$-CATG CCCAGGAGACCTGAT-3'; human TACI, 5'-GGTACCTGCATGTCCTGCAAA-3' and $5^{\prime}$-TGCAGTCCCTCAGGAGATGGT-3'; human BAFF-R, 5'-TGGGTCT GGTGAGCTGGA-3' and 5'-CCGGAGACAGAATGATGACCTT-3'; and human GAPDH, $\quad 5^{\prime}$-ACGGATTTGGTCGTATTGGGC $\quad-3^{\prime}$ and $5^{\prime}$-TTGACGGTGCCATG GAATTG - $3^{\prime}$

Cell proliferation assay. Cell growth was assessed using a Cell Counting Kit-8 (CCK-8) proliferation assay (Dojindo, Kumamoto, Japan). Cells $\left(5 \times 10^{3} / 100 \mu \mathrm{l}\right.$ per well) cultured in 96-well plates at indicated times were incubated with CCK-8 for the last $2 \mathrm{~h}$. Then the absorbance was measured at $450 \mathrm{~nm}$ using a microplate reader (Bio-Rad, Model 680).

Enzyme-linked immunosorbent assay. MM cells and MФs $\left(3 \times 10^{5} / \mathrm{ml}\right)$ were cultured alone in six-well plates for $48 \mathrm{~h}$. The supernatants harvested from $48 \mathrm{~h}$ cultures and those of BM of 27 patients with MM were measured for soluble BAFF using the Human BAFF/BLyS/TNFSF13B Quantikine enzyme-linked immunosorbent assay (ELISA) Kit (R\&D Systems), according to the manufacturer's instruction. The sensitivity of the kit was $6.44 \mathrm{pg} / \mathrm{ml}$. 
Flow cytometry: cell surface antigens and apoptosis. The expression of BAFF, BCMA, TACl, BAFF-R, CD68, CD163, and CD138 was measured by direct immunofluorescence using APC-conjugated CD68, CD138, TACl; PE-conjugated CD163, BAFF, BCMA; and FITC-conjugated BAFF-R. Each isotype control was determined to exclude the possibility of nonspecific influence. After staining, the cells were washed twice and then suspended in PBS and analyzed using a FACScan flow cytometer (BD Biosciences, San Diego, CA, USA).

The apoptotic cells were measured by staining cells using Annexin V-binding buffer (PharMingen, San Diego, CA, USA), along with Annexin V-FITC/propidium iodide, following the manufacturer's instructions. After incubating for $10 \mathrm{~min}$ at room temperature, the samples were detected by flow cytometry and apoptotic cells were analyzed using FlowJ07.6.1.

Western blot analysis. The cells were harvested, washed twice with PBS, and extracted using the lysis buffer containing a mixture of protease and phosphatase inhibitor (Thermo Fisher Scientific). The suspension was incubated for 30-60 min at $4{ }^{\circ} \mathrm{C}$, then centrifuged at 16000 r.p.m. for $30 \mathrm{~min}$ at $4^{\circ} \mathrm{C}$. The supernatant was then used as whole-cell lysates. The protein concentration was determined using the Bio-Rad Protein Assay. The samples were boiled at $95{ }^{\circ} \mathrm{C}$ for 5 min after mixing with a $4 \times$ sodium dodecyl sulfate (SDS) loading buffer (Invitrogen). The proteins $(20-40 \mu \mathrm{g})$ were subjected to $10 \%$ SDS-polyacrylamide gel electrophoresis and subsequently transferred to a polyvinylidene difluoride membrane (Merck Millipore, Darmstadt, Germany). The membranes were blocked with $5 \%$ bovine serum albumin for $1-2 \mathrm{~h}$ at room temperature. Then, the blots were incubated with primary antibodies overnight at $4^{\circ} \mathrm{C}$. Immunoblots were washed with Tris-buffered saline with Tween (TBST) buffer three times and incubated with HRPconjugated anti-mouse or anti-rabbit antibodies $(1: 5000)$ for $1 \mathrm{~h}$ at room temperature, followed by TBST washing three times and subsequent autoradiography with the ChemiDoc MP Imaging System (Bio-Rad) using an enhanced chemiluminescence detection kit (Biological Industries Israel Beit Haemek Ltd., Kibbutz Beit Hamek, Israel).

RNA interference. PBMC-induced MФs were transiently transfected with three siRNAs (TNSF13B-Homo-296:5'-CGCCUUACUUCUUGCCUUATT-3'; TNSF13B-Homo-700:5'-CUGCUUGCAACUGAUUGCATT-3'; TNSF13B-Homo973:5'-GCCUGAAACACUACCCAAUTT-3') against human BAFF (TNAF13B) and a scrambled nontargeting siRNA (GenePharm, Shanghai, China) using Lipo2000 (Life Technology, Pittsburgh, PA, USA). The BAFF-specific-siRNAt-ransfected MФs were co-cultured with MM cells with or without bort, and then evaluated in functional studies.

Immunofluorescence and immunohistochemistry analyses. Paraformaldehyde-fixed, Triton X-100 permeabilized cells of the BM biopsy tissues from patients with MM were used for immunofluorescence staining to analyze the expression of BAFF in CD68-expressing MФs. Also, paraformaldehyde-fixed, paraffin-embedded sections $(5 \mu \mathrm{m})$ of tumor tissues from tumor-bearing NOD-SCID (nonobese diabetic-severe combined immunodeficient) mice were used for immunohistochemistry staining to analyze CD68-expressing МФs and cleaved PARP (apoptotic tumor cells) as described earlier. ${ }^{44}$

MФ-mediated bort resistance of MM cells in vivo. Four-week-old female NOD-SCID mice were obtained from Vital River Laboratory Animal Technology Co. Ltd. (Beijing, China) and housed in the animal facility of Zhejiang University School of Medicine. The Tab of Animal Experimental Ethical Inspection of the First Affiliated Hospital, College of Medicine, Zhejiang University approved the procedures and protocols of all experiments. The mice were subcutaneously injected in the right flank with one million ARP-1 (control group) and one million ARP-1/two million monocytes both suspended in $100 \mu$ l of PBS. After palpable tumors (tumor diameter $\geqslant 5 \mathrm{~mm}$ ) developed, they were harvested for immunohistochemistry staining of CD68 to determine the infiltration of MФs. Some mice received intraperitoneal injections of bort $(2 \mu \mathrm{g} /$ mouse, every 3 days) for 2 weeks, and injections of PBS served as a control. In some experiments, the mice received intraperitoneal injections of BAFF-neutralizing antibody or control lgG2B (100 mg/ mouse, every 3 days), and administered with bort as described earlier. Tumor sizes were measured every 3 days using calipers and calculated using the formula $V=1 / 2\left(\right.$ length $\times$ width $\left.^{2}\right)$.

Statistical analysis. Data were analyzed using the GraphPad Prism 6 (GraphPad Software, LaJolla, CA, USA) and Microsoft Office Excel. All results were expressed as mean \pm standard deviation (S.D.), and the statistical differences among two groups were determined using a two-tailed Student's $t$-test. All $P$-values $<0.05$ were recognized as statistically significant. All experiments were performed in triplicate and three or more independent assays. ${ }^{*} P<0.05,{ }^{* *} P<0.01$, ${ }^{* \star *} P<0.001$

\section{Conflict of Interest}

The authors declare no conflict of interest.

Acknowledgements. This work was supported by National Natural Science Foundation of China (Project No. 31371380, No. 81201868, No. 91429302). We appreciate all staff from Zhejiang University School of Medicine and thank professor Qing Yi for guiding the experiments.

\section{Author contributions}

$\mathrm{DH}$ and ZC initiated the study, designed the experiment, JC and DH performed the majority of the experiments, JC wrote the manuscript. $Q C, L Y, X G, X L$ and $Y L$ performed the research, analyzed the data. WW, YY and EZ collected primary samples for the study. JH, QY, ZC supervised experiments.

\section{Publisher's Note}

Springer Nature remains neutral with regard to jurisdictional claims in published maps and institutional affiliations.

1. Viziteu E, Klein B, Basbous J, Lin YL, Hirtz C, Gourzones C et al. RECQ1 helicase is involved in replication stress survival and drug resistance in multiple myeloma. Leukemia 2017; 31: 2104-2113.

2. Fairfield $\mathrm{H}$, Falank $\mathrm{C}$, Avery L, Reagan MR. Multiple myeloma in the marrow: pathogenesis and treatments. Ann NYAcad Sci 2016; 1364: 32-51.

3. Rajkumar SV, Richardson PG, Hideshima T, Anderson KC. Proteasome inhibition as a novel therapeutic target in human cancer. $J$ clin oncol 2005; 23: 630-639.

4. Anderson KC. Progress and paradigms in multiple myeloma. Clin cancer res 2016; 22 : 5419-5427.

5. Bar-Natan M, Stroopinsky D, Luptakova K, Coll MD, Apel A, Rajabi H et al. Bone marrow stroma protects myeloma cells from cytotoxic damage via induction of the oncoprotein MUC1. Br j haematol 2017.

6. Lohr JG, Stojanov P, Carter SL, Cruz-Gordillo P, Lawrence MS, Auclair D et al. Widespread genetic heterogeneity in multiple myeloma: implications for targeted therapy. Cancer cell 2014; 25: 91-101.

7. Ruschak AM, Slassi M, Kay LE, Schimmer AD. Novel proteasome inhibitors to overcome bortezomib resistance. J Natl Cancer Inst 2011; 103: 1007-1017.

8. Frassanito MA, De Veirman K, Desantis V, Di Marzo L, Vergara D, Ruggieri S et al. Halting pro-survival autophagy by TGFbeta inhibition in bone marrow fibroblasts overcomes bortezomib resistance in multiple myeloma patients. Leukemia 2016; 30: 640-648.

9. Abdi J, Chen G, Chang $\mathrm{H}$. Drug resistance in multiple myeloma: latest findings and new concepts on molecular mechanisms. Oncotarget 2013; 4: 2186-2207.

10. Zheng Y, Yang J, Qian J, Qiu P, Hanabuchi S, Lu Y et al. PSGL-1/selectin and ICAM-1/CD18 interactions are involved in macrophage-induced drug resistance in myeloma. Leukemia 2013; 27: 702-710.

11. Moreaux J, Legouffe E, Jourdan E, Quittet $P$, Reme T, Lugagne $C$ et al. BAFF and APRIL protect myeloma cells from apoptosis induced by interleukin 6 deprivation and dexamethasone. Blood 2004; 103: 3148-3157.

12. Neri $\mathrm{P}$, Kumar S, Fulciniti MT, Vallet S, Chhetri S, Mukherjee $\mathrm{S}$ et al. Neutralizing B-cell activating factor antibody improves survival and inhibits osteoclastogenesis in a severe combined immunodeficient human multiple myeloma model. Clin cancer res 2007; 13: 5903-5909.

13. Hengeveld PJ, Kersten MJ. B-cell activating factor in the pathophysiology of multiple myeloma: a target for therapy? Blood cancer $\mathrm{j} 2015 ; \mathbf{5}$ : e282.

14. Raje NS, Moreau P, Terpos E, Benboubker L, Grzasko N, Holstein SA et al. Phase 2 study of tabalumab, a human anti-B-cell activating factor antibody, with bortezomib and dexamethasone in patients with previously treated multiple myeloma. Br j haematol 2016; 176: 783-795.

15. Vincent FB, Saulep-Easton D, Figgett WA, Fairfax KA, Mackay F. The BAFF/APRIL system: emerging functions beyond $\mathrm{B}$ cell biology and autoimmunity. Cytokine growth factor rev 2013; 24: 203-215.

16. Raje NS, Faber EA Jr., Richardson PG, Schiller G, Hohl RJ, Cohen AD et al. Phase 1 study of tabalumab, a human anti-B-cell activating factor antibody, and bortezomib in patients with relapsed/refractory multiple myeloma. Clin cancer res 2016; 22: 5688-5695. 
17. Moreaux J, Cremer FW, Reme T, Raab M, Mahtouk K, Kaukel P et al. The level of TACl gene expression in myeloma cells is associated with a signature of microenvironment dependence versus a plasmablastic signature. Blood 2005; 106: 1021-1030.

18. Tai YT, Li XF, Breitkreutz I, Song W, Neri P, Catley L et al. Role of B-cell-activating factor in adhesion and growth of human multiple myeloma cells in the bone marrow microenvironment. Cancer res 2006; 66: 6675-6682.

19. Montano Almendras CP, Thudium CS, Lofvall H, Moscatelli I, Schambach A, Henriksen K et al. Forced expression of human M-CSF in CD34+ cells promotes monocyte differentiation in vitro and in vivo but blunts osteoclastogenesis in vitro. Eur j haematol 2017; 98: 517-526.

20. Jaguin M, Houlbert N, Fardel O, Lecureur V. Polarization profiles of human M-CSFgenerated macrophages and comparison of M1-markers in classically activated macrophages from GM-CSF and M-CSF origin. Cell immunol 2013; 281: 51-61.

21. Mia S, Warnecke A, Zhang XM, Malmstrom V, Harris RA. An optimized protocol for human M2 macrophages using M-CSF and IL-4/IL-10/TGF-beta yields a dominant immunosuppressive phenotype. Scand $j$ immunol 2014; 79: 305-314.

22. Sierra-Filardi E, Nieto C, Dominguez-Soto A, Barroso R, Sanchez-Mateos P, Puig-Kroger A et al. CCL2 shapes macrophage polarization by GM-CSF and M-CSF: identification of CCL2/ CCR2-dependent gene expression profile. J Immunol 2014; 192: 3858-3867.

23. Na YR, Hong JH, Lee MY, Jung JH, Jung D, Kim YW et al. Proteomic analysis reveals distinct metabolic differences between granulocyte-macrophage colony stimulating factor (GM-CSF) and macrophage colony stimulating factor (M-CSF) grown macrophages derived from murine bone marrow cells. Mol cell proteom 2015; 14: 2722-2732.

24. Osman A, Bhuyan F, Hashimoto M, Nasser H, Maekawa T, Suzu S. M-CSF inhibits antiHIV-1 activity of IL-32, but they enhance M2-like phenotypes of macrophages. $J$ Immunol 2014; 192: 5083-5089.

25. Wang J, Hendrix A, Hernot S, Lemaire M, De Bruyne E, Van Valckenborgh E et al. Bone marrow stromal cell-derived exosomes as communicators in drug resistance in multiple myeloma cells. Blood 2014; 124: 555-566.

26. Bolkun L, Lemancewicz D, Jablonska E, Kulczynska A, Bolkun-Skornicka U, Kloczko J et al. BAFF and APRIL as TNF superfamily molecules and angiogenesis parallel progression of human multiple myeloma. Ann hematol 2014; 93: 635-644.

27. Demchenko YN, Brents LA, Li Z, Bergsagel LP, McGee LR, Kuehl MW. Novel inhibitors are cytotoxic for myeloma cells with NFkB inducing kinase-dependent activation of NFkB. Oncotarget 2014; 5: 4554-4566.

28. Ghosh S, Dass JF. Study of pathway cross-talk interactions with NF-kappaB leading to its activation via ubiquitination or phosphorylation: A brief review. Gene 2016; 584: 97-109.

29. Demchenko YN, Kuehl WM. A critical role for the NFkB pathway in multiple myeloma. Oncotarget 2010; 1: 59-68.

30. Hideshima T, Richardson P, Chauhan D, Palombella VJ, Elliott PJ, Adams J et al. The proteasome inhibitor PS-341 inhibits growth, induces apoptosis, and overcomes drug resistance in human multiple myeloma cells. Cancer res 2001; 61: 3071-3076.

31. Zheng Y, Cai Z, Wang S, Zhang X, Qian J, Hong S et al. Macrophages are an abundant component of myeloma microenvironment and protect myeloma cells from chemotherapy drug-induced apoptosis. Blood 2009; 114: 3625-3628.

32. Gutierrez-Gonzalez A, Martinez-Moreno M, Samaniego R, Arellano-Sanchez N, SalinasMunoz L, Relloso M et al. Evaluation of the potential therapeutic benefits of macrophage reprogramming in multiple myeloma. Blood 2016; 128: 2241-2252.
33. Wu X, Giobbie-Hurder A, Liao X, Connelly C, Connolly EM, Li J et al. Angiopoietin-2 as a biomarker and target for immune checkpoint therapy. Cancer immunol res 2017; 5 : $17-28$.

34. Caux C, Ramos RN, Prendergast GC, Bendriss-Vermare N, Menetrier-Caux C. A milestone review on how macrophages affect tumor growth. Cancer res 2016; 76: 6439-6442.

35. Chhabra S. Novel proteasome inhibitors and histone deacetylase inhibitors: progress in myeloma therapeutics. Pharmaceuticals 2017; 10 (doi:10.3390/ph10020040).

36. Moore PA, Belvedere O, Orr A, Pieri K, LaFleur DW, Feng P et al. BLyS: member of the tumor necrosis factor family and B lymphocyte stimulator. Science 1999; 285: 260-263.

37. Craxton A, Magaletti D, Ryan EJ, Clark EA. Macrophage- and dendritic cell-dependent regulation of human B-cell proliferation requires the TNF family ligand BAFF. Blood 2003; 101: $4464-4471$.

38. Karin M, Cao Y, Greten FR, Li ZW. NF-kappaB in cancer: from innocent bystander to major culprit. Nat rev Cancer 2002; 2: 301-310.

39. Mackay F, Figgett WA, Saulep D, Lepage M, Hibbs ML. B-cell stage and context-dependent requirements for survival signals from BAFF and the B-cell receptor. Immunol rev 2010; 237: 205-225.

40. Yang S, Li JY, Xu W. Role of BAFF/BAFF-R axis in B-cell non-Hodgkin lymphoma. Crit rev oncol/hematol 2014; 91: 113-122.

41. Su T, Li J, Meng M, Zhao S, Xu Y, Ding X et al. Bone marrow stromal cells induced activation of nuclear factor kappaB signaling protects non-Hodgkin's B lymphoma cells from apoptosis. Tumour biol 2016; 37: 10745-10752.

42. Kuo SH, Tsai HJ, Lin CW, Yeh KH, Lee HW, Wei MF et al. The B-cell-activating factor signalling pathway is associated with Helicobacter pylori independence in gastric mucosaassociated lymphoid tissue lymphoma without $t(11 ; 18)(q 21 ; q 21)$. J pathol 2017; 241 : 420-433.

43. Raje N, Longo DL. Monoclonal antibodies in multiple myeloma come of age. $N$ Engl j med 2015; 373: 1264-1266.

44. Zi FM, He JS, Li Y, Wu C, Yang L, Yang Y et al. Metformin displays anti-myeloma activity and synergistic effect with dexamethasone in in vitro and in vivo xenograft models. Cancer lett 2015; 356: 443-453.

(1) Cell Death and Disease is an open-access journal published by Nature Publishing Group. This work is licensed under a Creative Commons Attribution 4.0 International License. The images or other third party material in this article are included in the article's Creative Commons license, unless indicated otherwise in the credit line; if the material is not included under the Creative Commons license, users will need to obtain permission from the license holder to reproduce the material. To view a copy of this license, visit http://creativecommons.org/licenses/by/4.0/

(C) The Author(s) 2017

Supplementary Information accompanies this paper on Cell Death and Disease website (http://www.nature.com/cddis) 